\title{
Influence of drivers' visual and cognitive attention on their perception of changes in the traffic environment
}

\author{
Tina Cvahte Ojsteršek (D) and Darja Topolšek
}

\begin{abstract}
Drivers are met with numerous elements requiring their attention while driving. The present research focuses on selected visual and cognitive distractions that the driver is faced with, and on their influence on detecting and perceiving changes in the traffic environment. Driver self evaluation data was used to define which elements attract most visual and cognitive distraction. A constructed conceptual model was subjected to analysis using Exploratory factor analysis (EFA), Confirmatory factor analysis (CFA), and Structural Equation Modelling (SEM). Main findings show that thinking about personal problems, chores and errands as well as roadside advertisements on the cognitive side, and looking at advertisements and the natural environment on the visual side, present the most negative impacts on drivers' perception of crucial changes in the traffic environment. On the other hand, drivers that visually focus on traffic signals and pedestrians and think about driving speed, driving rules, and other traffic participants, tend to notice crucial changes in the traffic environment more often.
\end{abstract}

Keywords: Driver attention, Driver distraction, Cognitive attention, Visual attention, Traffic environment, Traffic safety

\section{Introduction}

Most adults carry out transport related activities daily. The driving itself often becomes routine, even in unknown traffic environments, which can present a significant cause for traffic accidents. In 2016, road injuries were the eighth top cause of deaths, killing 1.35 million people worldwide [43]. The occurrence of traffic accidents is influenced by many factors, which are generally divided into factors on the side of the driver, vehicle, and the environment. Because the driver is the most changing factor out of these, as it reflects the characteristics of each individual, research in this area is extremely important.

While driving, certain events or activities can distract the driver. The distraction can be minimal and have no effect on the driver's attention and driving performance, or it may be so extensive that the driver is no longer able to give the needed attention to the task of driving and consequently suffers from diminished driving performance [46]. Olson et al. [31] define a distraction as

\footnotetext{
* Correspondence: tina.cvahte@um.si

Faculty of Logistics, University of Maribor, Celje, Slovenia
}

occurring in the event of inattention, which causes a delay in recognizing information that is needed to safely perform a driving task. Lansdown, Stephens, and Walker [22] emphasize that there is no common definition of driver distraction currently valid, but they assess that the most appropriate definition would be that of Hedlund, Simpson, and Mayhew [15], who define distraction as an occurrence involving a diversion of attention of the driver due to the fact that the driver temporarily focuses on something (an object, person, task or event) that is not related to his driving, which consequently reduces his awareness, ability of decision making, and performance, which leads to a higher risk of the need for corrective actions, near-crashes and crashes. Reasons for driving distraction can be connected to any cognitive process, such as daydreaming, mind wandering, solving mathematical problems or various decision making, and to the use of information systems in the vehicle (radio, navigation, phones...), all of which can influence the driver's attention to the driving process [1]. Drivers are generally flexible and can adapt their behaviour connected to 
driving in a way that allows them to also fulfil an increased demand for activities not related to their driving [46].

Driver distraction reduces driver performance and presents an important factor in the occurrence of traffic accidents. Researches such as Treat et al. [40] and Wierwille et al. [42] found that driver factors (including driver errors) are the most common cause of traffic accidents / crashes. Moreover, Castro [4] reasons that over $90 \%$ of traffic accidents are the consequence of human error, and over $90 \%$ of those accidents are caused by visual information acquisition problems. Dingus et al. [8] and Singh [36] also confirm that drivers can be attributed with causing $90 \%$ or more critical situations in traffic.

The National Highway Traffic Safety Administration (NHTSA) divides driver distraction into four categories: visual (e.g. looking away from the roadway), auditory (e.g. responding to a ringing mobile phone), biomechanical (e.g. manually adjusting the radio volume), and cognitive (e.g. mind wandering) (Ranney, Garrott, and Goodman [33]). In their own assessment of recent trips, drivers reported lack of concentration (71.8\%), adjustments of vehicle equipment (68.7\%), looking at outside people, objects or events (57.8\%), and talking to other people in the car $(39.8 \%)$ as the most common distracting activities [27].

The tasks and activities carried out by the driver in the vehicle while driving are growing in scale and are consequently getting more distracting. In-vehicle activities that are not driving related and the resulting distractions have a proven negative impact on driving performance [16], increased number of driver errors [45], incidence of critical situations and traffic accidents [8], and severity of traffic accidents' outcome [30]. Probably the most common distracting factor, which is also most frequently explored in research, is the use of mobile phones. The use of these devices lowers driving precision [35], causes up to $50 \%$ slower responses to threats in comparison to driving without a mobile phone [3], and causes a reduction in performance [12]. The distracting effects are present even when using hands-free systems [11]. The driver is also largely influenced by activities, related to in-vehicle entertainment systems, such as changing the radio volume and alike [38, 44]. The use of navigation systems while driving has different effects on the efficiency of driving, which is connected to the manner of controlling the device, which can be manually operated or voice controlled. Tijerina et al. [39] found that devices which are manually operated take more attention from the driver, needing longer to operate them and taking their eyes off the road more often, in comparison to devices, operated by voice.

In addition to in-vehicle distraction, elements of the roadside can also present an important part of driver distraction. Even though observation of the traffic environment and roadside is an important activity during driving, some elements outside of the vehicle draw the drivers' attention and consequently present an important distraction. Roadside elements such as landscape heritage objects [2], roadside billboards and posters [28], and electronic billboards Dukic et al. [9], are found to be important distractors to the driver. Even though these elements present a potential distraction, their presence does not influence how drivers estimate the driving demand or riskiness of a certain road segment [6].

Another important distraction is mind wandering, being deep in thought or daydreaming. Mind wandering is a common occurrence that, according to Killingsworth and Gilbert [19], and Song and Wang [37], takes up 30-50\% of the time an individual is awake. This activity is often encountered in traffic as well, since drivers often "zone out" during driving, which consequently reduces their attentiveness for the traffic environment and can cause dangerous situations by reducing the driver's ability to process information from the environment [10] as well as by narrowing the visual scanning field of drivers [24]. The same research concludes that half of drivers attest to experiencing some mind wandering before causing a traffic accident. Qu et al. [32] studied the frequency and correlations of driver mind wandering and found that during times of wandering minds, drivers do not show many deficits in controlling the vehicle but tend to focus their visual attention narrowly on the road, therefore mind wandering can mean a reduced ability to monitor the environment. The authors also found that mind wandering is positively correlated to dangerous and risky driving, aggressive driving, negative cognitive/emotional driving styles, driving under the influence of alcohol and to a larger number of self-reported traffic accidents.

The above mentioned distractions are therefore crucial in the area of traffic safety from the driver perspective. Almahasneh et al. [1] find that the two most often noted distractions, visual distraction ("eyes-off-road") and cognitive distraction ("mind-off-road"), are important negative influencing factors for driving performance, such as lane variation, steering control, response to hazards, and visual perception efficiency, and that both distractions can even occur at the same time and are co-dependent. Charlton and Starkey [5] researched the effects of familiarity and automaticity on inattention blindness and detecting changes in the driving environment in a simulated environment. They found that many drivers drive without awareness and that driving in a familiar environment increases sensitivity to changes in road features associated with vehicle guidance and brings an improved performance on tasks not directly connected to driving.

Martens and Brouwer [26] used driving simulation to examine the influence of external distractions and internal cognitive processes on driving. Driver behaviour and physiological data were compared to the effects of a 
sound and speech task, presenting an external distraction. Researchers found that both internal and external distractions affected driving speed, number of lane changes, decreases in speed, and glances. Moreover, subjective evaluation from the drivers confirmed that they were less attentive to driving. Neyens and Boyle [29] examined cognitive, cell phone, in-vehicle, and passengerrelated distractions in relation to traffic accidents of teenage drivers and found that cognitive distractions more often resulted in rear-end crashes and angular collisions compared to fixed-object collisions. Similar outcomes in relation to physical and cognitive driver distractions and their influence on driving performance were found in other studies (e. g $[14,18]$.; Liu, Fu, and Lan [25]). Considering these results, it can be determined that driving distractions are an important subject for driving safety and therefore need to be examined further.

The present research will focus on the two major groups of distractions (visual and cognitive) and define whether the distracting factors influence drivers' perception of changes in the traffic environment. Previous research points to the importance of researching various driver distractions, which is the root of the present research as well, since it connects the influence of various distractions to the traffic environment. These changes are related to new advertisements, new or changed traffic signalization, changes of traffic regimes, and road work. Based on the above, two main hypotheses were formed:

H1. Visual attention to internal and external elements (eyes on or off the road) is connected to perceiving changes in the traffic environment.

H2. Cognitive attention to internal and external elements (mind on or off the road) is connected to perceiving changes in the traffic environment.

\section{Materials and methods}

In order to explore the connection between distractions and perceiving changes in the traffic environment, such as changes related to traffic signalization, changes in the traffic regime, and road work, a survey was conducted among Slovenian drivers of passenger cars. The objective is to determine the impact of each of the selected distractions, as described by the following measurements of distraction and perception of changes in the traffic environment:

(a) driver attention during driving ( $5=\mathrm{I}$ am very attentive to, $1=\mathrm{I}$ am not attentive to at all): car stereo (ATTEN_1), advertisements (ATTEN_2), natural environment (ATTEN_3), traffic signals (ATTEN_4), phone (ATTEN_5), driving speed (ATTEN_6), traffic lights (ATTEN_7), other vehicles and drivers (ATTEN_8), pedestrians (ATTEN_9);

(b) cognitive processes, i. e. thinking while driving ( 5 = I always think about, 1 = I never think about): personal problems (THINK_1), driving speed (THINK_2), driving rules (THINK_3), roadside advertisements (THINK_4), chores and errands (THINK_5), other traffic participants (THINK_6);

(c) the level of perception of changes in the traffic environment ( $5=\mathrm{I}$ always perceive changes, $1=\mathrm{I}$ never perceive changes): new roadside advertisements (TRAFF_CH_1), changes in traffic signs (TRAFF_CH_2), changes in traffic regimes (TRAFF_CH_3), road work (TRAFF_CH_4).

A construct or conceptual model encompassing three abstract variables and their proposed relationships was designed. These variables are not directly observable and should therefore be measured by other variables. The detailed structure of the conceptual model is presented in Fig. 1.

\subsection{Questionnaire}

In order to investigate the impact of driver distractions on their perception of changes in the traffic environment, a questionnaire was prepared to measure the levels of driver behaviour for elements of traffic and non-traffic environment and for mind wandering. The impact of these driving distractions on detecting changes in the traffic environment, changes in traffic signs, changes in the traffic regime, and road work, was measured. The respondents were instructed to think of their most often taken driving route (e.g. their daily commute to work) and to respond to the questionnaire with that route in mind, so the collected information presents the respondents' estimate of their overall driving experience. For a total of 19 variables, the respondents gave their level of attention or perceived changes on a 5 point Likert scale. The questionnaire also included control variables, namely age, average yearly amount of driven kilometres as a driver, amount of years having a driving licence for a car, and how many days a week the respondent drives a car.

A questionnaire like this is inevitably based on drivers' retrospective and subjective assessment of their driving experience, which is one of the main limitations of this research. Nonetheless, such questionnaires are one of the most often used tools in researching driving behaviour and perception, the most known example being the Driving behaviour questionnaire [34]. For the DBQ, Lajunen and Summala [21] found that drivers' self-evaluation is relatively reliable, but recommend an anonymous based research setting, and that is why the present research is based on a completely anonymous questionnaire. Additionally, research that compared drivers' objective visual 




Fig. 1 Conceptual model with proposed relationships and hypotheses

attention allocation via eye tracking with their selfevaluation (subjective) of visual attention allocation found that both sets of evaluation are conform to one another (see [41]), which gives additional validity to the method used in this research.

The research was performed among Slovenian drivers who completed the questionnaire online or via a printed version, both were completely anonymous. The questionnaire was disseminated on the researchers' institution's social media accounts (online) and in the institution's public space (printed version). Incomplete questionnaires were excluded, and the end sample consisted of 213 filled out questionnaires. Out of these, $38.4 \%$ respondents were male and mean respondent age was 25.32 years $(\mathrm{min}=18$ years, $\max =60$ years, $S D=6.06$ ). The average number of years the respondents have had their driving license for a car is a little less than 7 years $(M=6.88, \min =1, \max =$ $41, \mathrm{SD}=5.71$ ) and they drive a car on 5 days in a week $(\mathrm{M}=4.81, \min =0, \max =7, \mathrm{SD}=2.19)$. Most respondents' annual mileage is under $5000 \mathrm{~km}(29.9 \%)$ and from 5000 to $10,000 \mathrm{~km}(27.1 \%)$, and about a quarter drive more than $15,000 \mathrm{~km}$ yearly $(23.8 \%)$.

\subsection{Model}

The used conceptual model was subjected to analysis using Exploratory factor analysis (EFA), Confirmatory factor analysis (CFA), and Structural Equation Modelling (SEM).

One type of latent variables which are explicitly modelled in SEM or are a by-product of analysis using exploratory analysis techniques are so called factors. An EFA requirement is the non-correlation of uniqueness. In SEM, the term latent variables is commonly used to imply factors. The modelling in SEM is more mathematically oriented and allows for a broader spectre of models to be evaluated than with using EFA. Confirmatory factor analysis (CFA) or restricted factor analysis is a SEM application focused solely on relations between latent variables and their indicators, where the necessary restrictions cause CFA to be confirmatory and subjected to statistical testing. Using appropriate restrictions, specification, and testing of an array of factor models is permitted by CFA [17].

Based on EFA, the number and nature of the underlying factors (latent variables - constructs) that are responsible for the variability in the data were identified. Based on these factors, CFA was performed in order to test whether the measures of a latent construct (factor) are consistent with the researcher's understanding of the nature of that construct. After CFA, SEM was conducted. SEM is a statistical model that seeks to explain the relationships among multiple variables.

SPSS 22 software was used for EFA and AMOS 22 for CFA and SEM.

\section{Results}

Research results will focus on three main areas, represented by EFA, CFA, and SEM.

Factor analysis enables us to determine a smaller number of linear combinations of measured variables, so that they explain a large part of the data dispersion. EFA will thus enable the number and nature of the underlying factors (latent variables - constructs) to be determined. Thus, from a large number of measured variables related to driver attention while driving (ATTEN_1,..., ATTEN_ 9), cognitive processes (THINK_1,..., THINK_6), and the level of perception of changes in the traffic environment (TRAFF_CH_1,..., TRAFF_CH_4), a set of latent variables that represent what is common to the observed variables EFA will be determined. Thus, we predict that certain measured variables will be merged into latent variables. For example the variables in relation to driver attention while driving could, in principle, be merged into two latent variables, namely, onto a group of variables that would cover those associated with thinking while driving in a traffic environment and those related to thinking about things that are not related to the traffic environment. Consequently, only a small number of factors can be included the following steps instead of a large number of measured variables. EFA is followed by 
CFA, where the main objective is to investigate whether the data fit the hypothesized measurement model. The structure of the model of factors was derived from EFA, which was used as a baseline when conducting the CFA analysis. CFA validated the model structure against the existing measurement theory. CFA will in essence define whether there is a connection among the set of measured variables and their constructs, which means we will test whether certain variables precisely define a specific latent variable.

SEM will be performed based on EFA and CFA. Structural equation modelling is a class of statistical models which aim to explain the relationships among multiple variables. SEM will enable evaluation of relationships between measureable and latent variables and relationships among latent variables. During the process of SEM modelling, control constructs are included with one element (factors age, average yearly amount of driven kilometres as a driver, amount of years having a driving licence for a car, and how many days a week the respondent drives a car).

\subsection{Exploratory factor analysis}

A normality test must be performed in order to successfully perform EFA, since it is the basis for choosing a method for estimating the factor loadings and the variances. Normality was studied by observing the skewness and kurtosis of the data. Both skewness and kurtosis were inside desired limits as recommended by Kline [20], Lei and Lomax [23], and Curran, West, and Finch [7].

Concerning normality in data distribution, Maximum likelihood method (Promax rotation) was used for estimating (ML). Its main advantage is the calculation of a wide range of indexes for the model's goodness of fit. For determining reliability, Bartlett's test of sphericity (BTS) and the Kaiser-Meyer-Olkin (KMO) test were performed. The BTS test was highly significant at $X^{2}=842$, 466 with $\mathrm{df}=91$ and $p<0.001$, while the value of $\mathrm{KMO}$ was $0.774>0.5$. We can determine based on these tests that the factor analysis is reliable.

The size of factor loadings normally reflects the convergent validity with high correlations between variables within a single factor. Because sample size affects sufficient or significant loadings, the required loadings are higher when the sample size is smaller. In our sample size of 213 completed questionnaires, a factor loading of at least 4.40 is recommended [13], which was achieved.

Table 1 shows the EFA results, which include Cronbach's alphas. Cronbach's alpha is a measure used for the determination of the reliability of internal consistency of the factors that EFA extracted. Generally speaking, this represents an evaluation of the degree of consistency between multiple measurements of a certain variable, meaning that a "reliable" set of variables will be consistently loaded onto the same factor.
Table 1 Achieved results of the rotated factor pattern matrix (exploratory factor analysis)

\begin{tabular}{llllll}
\hline Pattern Matrix & \multicolumn{1}{l}{ Factor } & & & \\
\cline { 2 - 6 } & 1 & 2 & 3 & 4 & 5 \\
\hline Cronbach Alpha & 0.882 & 0.822 & 0.784 & 0.753 & 0.728 \\
TRAFF_CH_4 & .984 & & & & \\
TRAFF_CH_3 & .885 & & & & \\
TRAFF_CH_2 & .660 & & & & \\
THINK_2 & & .913 & & & \\
THINK_3 & & .815 & & & \\
THINK_6 & & .645 & & & \\
ATTEN_9 & & & .871 & & \\
ATTEN_4 & & & .744 & & \\
ATTEN_7 & & & .671 & & \\
ATTEN_2 & & & & .989 & \\
ATTEN_3 & & & & & \\
THINK_5 & & & & & \\
THINK_1 & & & & & \\
THINK_4 & & & & & \\
\hline
\end{tabular}

Table 1 shows the EFA results, which include Cronbach's alphas. According to Hair et al. [13], the generally agreed minimal lower limit for Cronbach's alpha is 0.70 .

EFA results show that variables, connected to perceiving changes in the traffic environment, are significantly loaded on the corresponding factor 1 , which can be called "Perceived changes" (TRAFF_CH_2, 3, 4) due to included variables. Variables named THINK_x are derived from the question on what drivers think about while driving. For variables of Driving speed (THINK_2), Driving rules (THINK_3), and Other traffic participants (THINK_6), the corresponding factor is called "Mindon-road" since it shows that the driver's cognitive processes are concerned with their driving. Other variables from this question about Personal problems (THINK_1), Roadside advertisements (THINK_4), and Chores and errands (THINK_5) are significantly loaded on the corresponding factor 5, which can be called "Mind-offroad". Variables about driver attention during driving for Traffic signals (ATTEN_4), Traffic lights (ATTEN_7), and Pedestrians (ATTEN_9) are significantly loaded on the corresponding factor 3, named "Eyes-on-road". Variables Advertisements (ATTEN_2) and Natural environment (ATTEN_3) are connected to factor 4, so called "Eyes-off-road".

\subsection{Confirmatory factor analysis}

To test the consistency of latent construct measures (factors) with understanding of the nature of the construct as set in the research, confirmatory factor analysis is used. Loading factors, derived from EFA, are assigned 
to confirmatory factor analysis. Maximum likelihood method was used in CFA due to multivariate normality. Based on various author recommendations, different model fits were tested in CFA, which were above the recommended values. Additionally, Composite (construct) Reliability (CR) and Average Variance Extracted (AVE) were tested. Composite reliability reached over the limit of 0.50 (from 0.562 to 0.648 ) and AVE values surpassed 0.70 (from 0.751 to 0.885 ).

\subsection{Structural equation model}

Since it is a combination of confirmatory factor analysis and regression analysis or simultaneous equations models, structural equation modelling is being more and more used in modelling various relationships between unmeasurable factors.

As in CFA, maximum likelihood estimation method was used in SEM. Certain additional factors are also important for this research, such as the influence of control variables on the driver's perception of changes in the traffic environment. These were driver age, how many days in a week the participant is involved in traffic, and how many kilometres they drive in a year.

After the finished estimation, GOF indexes were calculated. As in CFA, these indices provided evidence of a good model fit, since their achieved values were $\chi^{2}=130.239, \chi^{2}$ / $\mathrm{df}=1.240, \quad \mathrm{GFI}=0.922, \quad \mathrm{NFI}=0.932, \quad \mathrm{TLI}=0.963, \quad \mathrm{CFI}=$ $0.971, \mathrm{RMSEA}=0.037, \mathrm{SRMR}=0.0636, \mathrm{IFI}=0.972$.
Figure 2 shows a graphical representation of the standardized SEM model with the estimated path coefficients significant at $p \leq 0.10$ level among the variables; insignificant paths are not shown in Fig.2 (amount of years having a driving licence for a car, and how many days a week the respondent drives a car). The SEM model is represented by the path diagram, and it includes the measurement part of the model (influences of measurable variables onto latent variables, e.g. the connections between Eyes-on-road and ATTEN_9, ATTEN_4 in ATTEN_7) and the structural part of the model (influences or connection among latent variables, e.g. the influence of Eyes-on-road to Perceived changes). The paths that are significant have the corresponding standardized weights marked.

\subsubsection{Relationship between measured and latent variables}

The EFA and CFA revealed five latent variables: Perceived changes, Mind-on-road, Mind-off-road, Eyes-onroad, and Eyes-off-road.

The latent variable "Perceived changes" was constructed, based on EFA and CFA, with 3 measured variables which covered a wide range of traffic sign changes and changes in traffic regimes as well as road work. From the path coefficient, it is obvious that drivers most often perceived road work, which can be explained by the fact that it is the most visually obvious change among the observed. This also suggests that perceiving

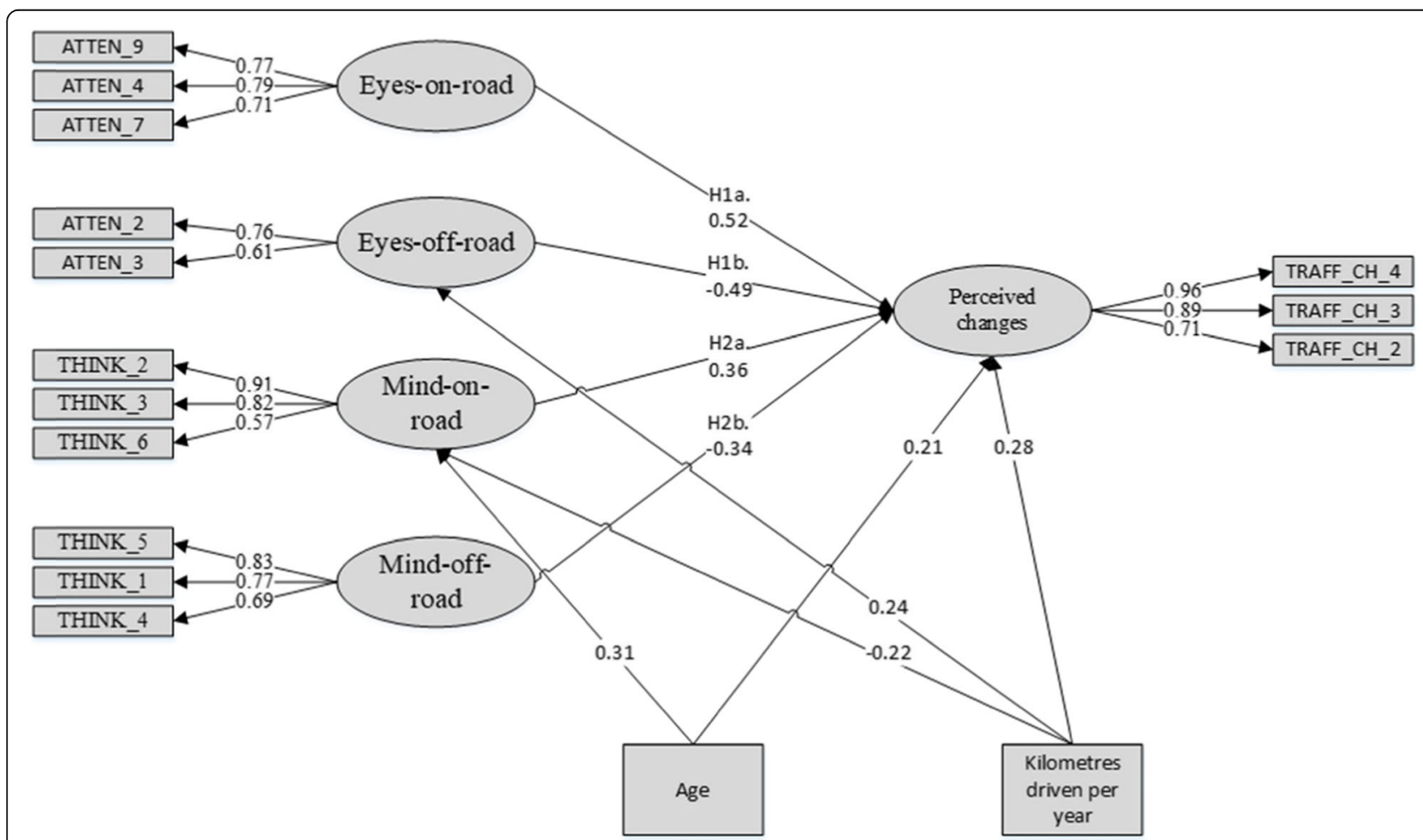

Fig. 2 SEM of relationships between visual and cognitive attention and perception of changes in the traffic environment 
road work is more important for drivers than other changes. The latent variable "Eyes-on-road" is presented by 3 measured variables, which covered different traffic concerned elements. The SEM revealed that the largest coefficient refers to "Traffic signals" (ATTEN_4), and to "Pedestrians" (ATTEN_9), which means that drivers are most attentive to traffic signalization and pedestrians, who are the most vulnerable group of traffic participants. Factor "Eyes-off-road" includes only two measured variables representing Advertisements (ATTEN_2) and Natural environment (ATTEN_3). These variables can have a significant effect on the level of traffic safety, since they attract driver attention and steer it away from the traffic environment. The latent variable "Mind-on road" was constructed by 3 measured variables, which covered a range of different cognitive or thinking processes concerned with the traffic environment. From the path coefficient, it is obvious that variable "Driving speed" (THINK_2) had the largest coefficients in constructing "Mind-on road". "Mind-off-road" is the last constructed latent variable and is represented by 3 measured variables, which covered a wide range of cognitive processes concerned with mind wandering elements, such as "Personal problems" (THINK_1), "Roadside advertisements" (THINK_4) and "Chores and errands" (THINK_5). From the path coefficient, it is obvious that thinking about chores and errands (THINK_5) had the largest coefficients in constructing "Mind-off-road".

\subsubsection{Relationship among latent variables}

The SEM results also identified six significant relations among the 5 latent variables that were consistent with the hypotheses. First positive relation is between "Eyes-onroad" and "Perceived changes". This indicates that drivers who are more attentive to what is happening in the traffic environment and pay more attention to it are more likely to notice and perceive changes within the traffic environment. The path coefficient between "Eyes-off-road" and "Perceived changes" is negative, meaning that drivers who more often observe elements outside of the immediate traffic environment perceive less changes in the traffic environment itself. In the case of a positive relation between "Mind-on-road" and "Perceived changes" and the negative relation between "Mind-off-road" in "Perceived changes" it can be found that drivers who more often think about their personal problems or other non-traffic related issues are less likely to perceive changes in the traffic environment.

Additionally, the influence of some control variables (age, number of yearly driven kilometres, amount of years having a driving licence for a car, and how many days a week the respondent drives a car) on the latent variables was also studied. The variables pointing to the amount of years having a driving licence for a car and how many days a week the respondent drives a car did not give significant results (estimated path coefficients is not significant at $p \leq 0.05, p$ value was not under 0.05 but over 0.205 ) and were consequently excluded from the SEM model results. SEM results show that as the drivers age, they become more attentive to the traffic environment and also think more about its elements, which can be confirmed with a positive value of the path coefficient among the control variable "Age" and "Mindon-road". Older drivers also more perceive changes in the traffic environment more often, as shown by the positive path coefficient value among "Age" and "Perceived changes". The other control variable, number of kilometres a driver drives in their car per year, gave significant results in three cases: the path coefficients with "Mind-on-road" (-0.22), with "Eyes-off-road" (0.24) and with "Perceived changes" (0.28). From these results, it can be stated that drivers who drive larger distances per year are less attentive to the traffic environment, think about it less, and more frequently focus on elements outside of the relevant traffic environment. At the same time, these drivers more frequently notice and perceive various changes in the traffic environment, which can suggest that their experience, especially in a certain environment they know and are accustomed to, gives them the advantage of better detection of untypical situations.

\section{Discussion}

Inevitably, drivers do not always focus on the road and the traffic situation at hand. Distractions that occur either internally or externally (i.e. are cognitive or visual) have a great effect on their perception of the traffic environment and consequently on their driving safety. The present research set out to determine what cognitive and visual elements affect a driver's attention to the traffic environment as presented by their perception of changes in said environment.

Results of the constructed model showed that both visual and cognitive attention are connected to perceiving changes in the traffic environment, therefore confirming the set hypotheses. Out of the nine potential visual elements, advertisements and the natural environment represent the visual elements that most distract the driver to take his eyes away from the relevant traffic environment, and out of six cognitive elements, thinking about chores and errands, personal problems, and roadside advertisements pose the greatest threats for mind wandering during driving. It is interesting to note however that out of the given elements of the traffic and roadside environment, new roadside advertisements were not a significant part of perceived changes.

Experience seems to have a negative effect on attention during driving, since those that drive more kilometres yearly tend to experience more instances of visual distractions outside of the traffic environment and their mind is 
focused on the road less. However, as in rising age, these drivers notice more changes in the traffic environment. This could be explained with the role of experience in the act of driving, since drivers come to expect a normal state of the traffic environment and can therefore put more focus outside of it, but also tend to notice anything out of the ordinary sooner and can react to changes more appropriately.

An important limitation of the present research, even though the model showed great reliability, is that it is based on self-evaluation of general driving experience rather than on external objective evaluation. Therefore, the authors propose that in the future, similar research should be performed with some form of objective measuring of visual and cognitive distractions while at the same time measuring drivers' perception of changes in their traffic environment in real time.

\section{Conclusion}

Overall, the importance of the results of the present research lies mainly in knowing what aspects traffic safety initiatives should focus on most and what elements potentially pose the largest threats to driver attention. Policy makers and practitioners should develop focused programs aimed at educating drivers on the plethora of elements that influence their driving capabilities and focus, and encourage mindful driving with a sufficient visual and cognitive focus on the driving tasks and traffic environment.

\section{Acknowledgements}

Not applicable.

\section{Authors' contributions}

TCO and DT cooperated equally on the manuscript preparation and both read and approved the final manuscript. TCO managed the survey application and DT managed the modelling and analysis.

\section{Funding}

Part of this research is based on a survey, performed in the frame of the project "Po kreativni poti do praktičnega znanja (Practical knowledge through creative pathways)", co-funded by the European Social Fund and conducted within the framework of the Operational Programme for Human Resources Development, development priority 1: Promoting entrepreneurship and adaptability, priority axis 1.3: Scholarship schemes.

\section{Availability of data and materials}

The datasets used and/or analysed during the current study are available from the corresponding author on reasonable request.

\section{Competing interests}

The authors declare that they have no competing interests.

Received: 2 August 2019 Accepted: 23 October 2019

Published online: 08 November 2019

\section{References}

1. Almahasneh, H., Chooi, W. T., Kamel, N., \& Malik, A. S. (2014). Deep in thought while driving: An EEG study on drivers' cognitive distraction. Transport Res F: Traffic Psychol Behav, 26, 218-226. https://doi.org/10.1016/j. trf.2014.08.001.

2. Antonson, H., Ahlström, C., Mårdh, S., Blomqvist, G., \& Wiklund, M. (2014). Landscape heritage objects' effect on driving: A combined driving simulator and questionnaire study. Accid Anal Prev, 62, 168-177. https://doi.org/10. 1016/j.aap.2013.09.021

3. Burns, P. C., Parkes, A., Burton, S., Smith, R. K., \& Burch, D. (2002). How dangerous is driving with a mobile phone? Benchmarking the impairment to alcohol (no. TRL547). Berks: Transport Research Laboratory https://trl.co.uk/ sites/default/files/TRL547.pdf.

4. Castro, C. (2008). Visual demands and driving. In C. Castro (Ed.), Human factors of visual and cognitive performance in driving (pp. 2-26). Boca Raton: CRC Press.

5. Charlton, S. G., \& Starkey, N. J. (2013). Driving on familiar roads: Automaticity and inattention blindness. Transport Res F: Traffic Psychol Behav, 19, 121-133. https://doi.org/10.1016/j.trf.2013.03.008.

6. Charlton, S. G., \& Starkey, N. J. (2017). Drivers' mental representations of familiar rural roads. J Environ Psychol, 50, 1-8. https://doi.org/10.1016/j.jenvp.2017.01.003.

7. Curran, P. J., West, S. G., \& Finch, J. F. (1996). The robustness of test statistics to nonnormality and specification error in confirmatory factor analysis. Psychol Methods, 1, 16-29. https://doi.org/10.1037/1082-989X.1.1.16.

8. Dingus, T. A., Guo, F., Lee, S., Antin, J. F., Perez, M., Buchanan-King, M., \& Hankey, J. (2016). Driver crash risk factors and prevalence evaluation using naturalistic driving data. Proc Natl Acad Sci, 113(10), 2636-2641. https://doi. org/10.1073/pnas.1513271113.

9. Dukic, T., Ahlstrom, C., Patten, C., Kettwich, C., \& Kircher, K. (2013). Effects of Electronic Billboards on Driver Distraction. Traffic Injury Prevention, 14(5), 469-76. https://doi.org/10.1080/15389588.2012.731546.

10. Galéra, C., Orriols, L., M'Bailara, K., Laborey, M., Contrand, B., Ribéreau-Gayon, R., Masson, F., Bakiri, S., Gabaude, C., Fort, A., Maury, B., Lemercier, C., Cours, M., Bouvard, M. P., \& Lagarde, E. (2012). Mind wandering and driving: Responsibility case-control study. BMJ, 345. https://doi.org/10.1136/bmj.e8105.

11. Garrison, T. M., \& Williams, C. C. (2013). Impact of relevance and distraction on driving performance and visual attention in a simulated driving environment. Appl Cogn Psychol, 27(3), 396-405. https://doi.org/10.1002/acp.2917.

12. Haigney, D. E., Taylor, R. G., \& Westerman, S. J. (2000). Concurrent mobile (cellular) phone use and driving performance: Task demand characteristics and compensatory processes. Transport Res F: Traffic Psychol Behav, 3(3), 113-121. https://doi.org/10.1016/S1369-8478(00)00020-6.

13. Hair, J. F., Black, W. C., Babin, B. J., \& Anderson, R. E. (2010). Multivariate Data Analysis. New Jersey: Prentice Hall.

14. Harbluk, J. L., Noy, Y. I., Trbovich, P. L., \& Eizenman, M. (2007). An on-road assessment of cognitive distraction: Impacts on drivers' visual behavior and braking performance. Accid Anal Prev, 39(2), 372-379. https:/doi.org/10.1016/j.aap.2006.08.013.

15. Hedlund, J., Simpson, H., \& Mayhew, D. (2006). Summary of Proceedings and Recommendations. Presented at the international conference on distracted driving. Ottawa: The Traffic Injury Research Foundation, The Canadian Automobile Association

16. Horberry, T., Anderson, J., Regan, M. A., Triggs, T. J., \& Brown, J. (2006). Driver distraction: The effects of concurrent in-vehicle tasks, road environment complexity and age on driving performance. Accid Anal Prev, 38(1), 185-191. https://doi.org/10.1016/j.aap.2005.09.007.

17. Hoyle, R. H. (2012). Handbook of structural equation modeling. New York: The Guilford Press.

18. Kaber, D. B., Liang, Y., Zhang, Y., Rogers, M. L., \& Gangakhedkar, S. (2012). Driver performance effects of simultaneous visual and cognitive distraction and adaptation behavior. Transportation research part F: traffic psychology and behavior, 15(5), 491-501. https://doi.org/10.1016/j.trf.2012.05.004.

19. Killingsworth, M. A., \& Gilbert, D. T. (2010). A wandering mind is an unhappy mind. Science, 330(6006), 932-932. https://doi.org/10.1126/science.1192439.

20. Kline, R. B. (2011). Principles and practice of structural equation modeling. New York: The Guilford Press.

21. Lajunen, T., \& Summala, H. (2003). Can we trust self-reports of driving? Effects of impression management on driver behaviour questionnaire responses Transportation research part F: traffic psychology and behaviour, 6, 97-107. https://doi.org/10.1016/\$1369-8478(03)00008-1.

22. Lansdown, T. C., Stephens, A. N., \& Walker, G. H. (2015). Multiple driver distractions: A systemic transport problem. Accid Anal Prev, 74, 360-367. https://doi.org/10.1016/j.aap.2014.07.006.

23. Lei, M., \& Lomax, R. G. (2005). The effect of varying degrees of nonnormality in structural equation modeling. Struct Equ Model Multidiscip J, 12(1), 1-27. https://doi.org/10.1207/s15328007sem1201_1.

24. Lemercier, C., Pêcher, C., Berthié, G., Valéry, B., Vidal, V., Paubel, P. V., Cour, M. Fort, A., Galera, C., Gabaude, C., Lagarde, E., \& Maury, B. (2014). Inattention behind the wheel: How factual internal thoughts impact attentional control while driving. Saf Sci, 62, 279-285. https://doi.org/10.1016/j.ssci.2013.08.011. 
25. Liu, Z. F., Fu, R., \& Lan, Z. (2016). The Comparison between Visual Distraction and Cognitive Distraction. In COTA International Conference of Transportation Professionals 2016 (pp. 1525-1535). https://doi.org/10.1061/ 9780784479896.139

26. Martens, M. H., \& Brouwer, R. F. T. (2013). Measuring being lost in thought: An exploratory driving simulator study. Transport Res F: Traffic Psychol Behav, 20, 17-28. https://doi.org/10.1016/j.trf.2013.04.002.

27. McEvoy, S. P., Stevenson, M. R., \& Woodward, M. (2006). The impact of driver distraction on road safety: Results from a representative survey in two Australian states. Injury Prevention, 12(4), 242-247. https://doi.org/10.1136/ip. 2006.012336.

28. Missokefalou, E., \& Eliou, N. (2012). Recording and evaluation procedure of drivers' distraction: The case of Thessaloniki ring road. Procedia Soc Behav Sci, 48, 3159-3169. https://doi.org/10.1016/j.sbspro.2012.06.1282.

29. Neyens, D. M., \& Boyle, L. N. (2007). The effect of distractions on the crash types of teenage drivers. Accid Anal Prev, 39(1), 206-212. https://doi.org/10. 1016/j.aap.2006.07.004

30. Neyens, D. M., \& Boyle, L. N. (2008). The influence of driver distraction on the severity of injuries sustained by teenage drivers and their passengers. Accid Anal Prev, 40(1), 254-259. https://doi.org/10.1016/j.aap.2007.06.005.

31. Olson, R. L., Hanowski, R. J., Hickman, J. S., \& Bocanegra, J. (2009). Driver distraction in commercial vehicle operations. No. FMCSA-RRT-09-042. Blacksburg, VA: Federal Motor Carrier Safety Administration.

32. Qu, W., Ge, Y., Xiong, Y., Carciofo, R., Zhao, W., \& Zhang, K. (2015). The relationship between mind wandering and dangerous driving behavior among Chinese drivers. Saf Sci, 78, 41-48. https://doi.org/10.1016/j.ssci.2015.04.016.

33. Ranney, T. A., Garrott, W. R., \& Goodman, M. J. (2001). NHTSA driver distraction research: Past, present, and future. No. 2001-06-0177. SAE technical paper, 2001.

34. Reason, J. T., Manstead, A. S. R., Stradling, S. G., Baxter, J. S., \& Campbell, K. (1990). Errors and violations on the road: A real distinction? Ergonomics, 33, 1315-1332.

35. Reed, M. P., \& Green, P. A. (1999). Comparison of driving performance onroad and in a low-cost simulator using a concurrent telephone dialling task Ergonomics, 42(8), 1015-1037. https://doi.org/10.1080/001401399185117.

36. Singh, S. (2015). Critical Reasons for Crashes Investigated in the National Motor Vehicle Crash Causation Survey. No. DOT HS 812115 traffic safety facts crash.stats. Washington, DC: National Highway Traffic Safety Administration.

37. Song, X., \& Wang, X. (2012). Mind wandering in Chinese daily lives-an experience sampling study. PLoS One, 7(9), e44423. https://doi.org/10.1371/ journal.pone.0044423.

38. Stutts, J. C., Reinfurt, D. W., Staplin, L., \& Rodgman, E. A. (2001). The role of driver distraction in traffic crashes. Washington D. C: AAA Foundation for Traffic Safety.

39. Tijerina, L., Johnston, S., Parmer, E., Winterbottom, M. D., \& Goodman, M. (2000). Driver distraction with wireless telecommunications and route guidance systems. No. HS-809 069. East liberty, OH: Department of Transportation, National Highway Traffic Safety Administration.

40. Treat, J. R., Tumbas, N. S., McDonald, S. T., Shinar, D., Hume, R. D., Mayer, R. E. , Stansifer, R. L., \& Castellan, N. J. (1979). Tri-level study of the causes of traffic accidents: final report. No. DOT HS 805 099. Bloomington, IN: Institute for Research in Public Safety.

41. Werneke, J., \& Vollrath, M. (2012). What does the driver look at? The influence of intersection characteristics on attention allocation and driving behaviour. Accident Analysis \& Prevention, 45, 610-619. https://doi.org/10. 1016/j.aap.2011.09.048.

42. Wierwille, W. W., Hanowski, R. J., Hankey, J. M., Kieliszewski, C. A., Lee, S. E., Medina, A., \& Dingus, T. A. (2002). Identification of driver errors: overview and recommendations. No. FHWA-RD-02-003. United States: Federal Highway Administration.

43. World Health Organization. (2018). Global status report on road safety 2018. Geneva: World Health Organization

44. Young, K. L., Mitsopoulos-Rubens, E., Rudin-Brown, C. M., \& Lenné, M. G. (2012). The effects of using a portable music player on simulated driving performance and task-sharing strategies. Appl Ergon, 43(4), 738-746. https:// doi.org/10.1016/j.apergo.2011.11.007.

45. Young, K. L., Salmon, P. M., \& Cornelissen, M. (2013). Distraction-induced driving error: An on-road examination of the errors made by distracted and undistracted drivers. Accid Anal Prev, 58, 218-225. https://doi.org/10.1016/j. aap.2012.06.001
46. Young, K., \& Regan, M. (2007). Driver distraction: A review of the literature. In I. J. Faulks, M. Regan, M. Stevenson, J. Brown, A. Porter, \& J. D. Irwin (Eds.), Distracted driving (pp. 379-405). Australasian College of Road Safety: Sydney, NSW.

\section{Publisher's Note}

Springer Nature remains neutral with regard to jurisdictional claims in published maps and institutional affiliations.

\section{Submit your manuscript to a SpringerOpen ${ }^{\circ}$ journal and benefit from:}

- Convenient online submission

- Rigorous peer review

- Open access: articles freely available online

- High visibility within the field

- Retaining the copyright to your article

Submit your next manuscript at $\boldsymbol{\nabla}$ springeropen.com 